\title{
Makna Simbolik Ritual Mabbaca-Baca di Kelurahan Ujung Tanah Kecamatan Cenrana Kabupaten Bone
}

\author{
Syarifah Nur Fajrin ${ }^{1}$ Shermina Oruh ${ }^{2}$ Andi Agustang ${ }^{3}$ \\ ${ }^{1}$ Mahasiswa Pascasarjana S3 Sosiologi Universitas Negeri Makassar \\ Email: syarifahnurf98@gmail.com \\ 2 Dosen Universitas Pejuang Republik Indonesia \\ Email: shoruh68@gmail.com \\ 2 Dosen Universitas Negeri Makassar \\ Email: andiagust63@gmail.com
}

\begin{abstract}
This study aims to determine the symbolic meaning of the mabbaca-baca ritual and to analyze the implementation of Mabbaca-baca in Ujung Tanah Village, Cenrana District, Bone Regency. qualitative descriptive. The results show that the meaning of reading-reading is a mandate that is passed on to the successor then the meaning of reading-reading in terms of the most important material used is the tool used as a delivery then in terms of the materials used during implementation is the most common meaning expressed among them asking for protection and apologies for the mistakes made so that in the future they can live life in a calm manner and the mabaca-baca ritual procession is what everyone in the environment and families who have time come to prepare everything needed, the community in the reading-reading process dividing tasks so that they trust each other in carrying out these tasks and readings are said there are already specially prepared when performing any rituals, everything is the same and automatically preparations are also in doing the mabaca process is also the same which aims to make the prayers that are said and done. it's accepted.
\end{abstract}

Keywords : Meaning; Ritual; Mabaca-baca

\begin{abstract}
Abstrak. Penelitian ini bertujuan untuk mengetahui makna simbolik ritual mabbaca-baca dan untuk menganalisis pelaksanaan Mabbaca-baca di Kelurahan Ujung Tanah, Kecamatan Cenrana Kabupaten Bone Penelitian ini merupakan penelitian fenomenologi dengan menggunakan 4 informan dengan metode pengumpulan data menggunakan metode Observasi, Wawancara dan Dokumentasi serta dianalisis secara deskriptif kualitatif. Hasil penelitian menunjukan bahwa makna mabaca-baca adalah amanah yang di wariskan kepada penerusnya kemudian arti ma baca baca dari segi bahan yang paling utama di gunakan ialah alat yang digunakan sebagai penyampaian kemudian dari segi bahan yang digunakan saat pelaksanaan ialah arti yang paling umum diungkapkan di antaranya memohon perlindungan dan permintaan maaf atas kesalahan yang dilakukan agar kedepanya dapat menjalankan kehidupan dengan tenag dan proesesi ritual mabaca-baca adalah yang dilakukan semua orang yang ada dilnkungan tersebut dan keluarga yang ada waktunya datang untuk mempersiapkan segala sesuatu yang dibutuhkan, para masyarakat dalam proses mabca baca membagi tugas agar saling mempercayai dalam melaksanakan tugas tersebut dan bacaan di ucapkan sudah memang ada yang disiapkan secara khusus saat melakukan ritual apapun itu semuanya sama dan secara otomatis persiapan pun juga dalam melakukan proses mabaca juga sama yang bertujuan agara doa yang di utarakan dapat dikabulkan.
\end{abstract}

Kata Kunci : Makna; Ritual; Mabaca-baca 


\section{PENDAHULUAN}

Indonesia adalah Negara majemuk yang memiliki beragam ciri khas, agama, tradisi, dan kebudayaan. Ketika membahas tentang tradisi yang ada di Indonesia seakan tak bisa dilepaskan dari peradaban manusia sebelumnya atau leluhurnya yang mengandung norma dan nilai yang sangat melekat pada masyarakat yang menganut tradisi tersebut. Kebudayaan dan tradisi yang beraneka ragam itu masih kita saksikan hingga sekarang ini. Berbicara tentang budaya, Budaya merupakan hasil pemikiran dan gagasan yang dijadikan cara hidup yang berkembang dimiliki oleh suatu kelompok dan diwariskan dari generasi ke generasi. Budaya mengandung arti penting dalam masyarakat. meskipun ada beberapa kalangan masyarakat yang menganggap kebudayaan yang dilakukan oleh sebagian masyarakat yang lain dianggap bertentangan dengan agama. Perlu diketahui bahwa agama bersumber dari Allah, budaya bersumber dari manusia, akan tetapi tidak berarti keduanya tidak terkait sama sekali melainkan memiliki hubungan yang erat. Ajaran Allah yang disebut agama, mewarnai corak budaya. (Ii, B. A. B., Beatty, A., Hefner, R. W., Mulder, N., Syam, N., \& Manan, 2001).

Tradisi-tradisi di Indonesia ada begitu banyak, setiap daerah memiliki tradisi masing-masing yang rutin dilaksanakan oleh masyarakat daerah tersebut, sama halnya di Sulawesi Selatan yang memiliki 4 suku besar yaitu Bugis, Makassar, Toraja, dan Mandar di setiap suku itu memiliki budaya dan tradisi masing-masing. Masyarakat Bugis dikenal memiliki budaya atau tradisi yang sangat kental salah satunya terletak di Kabupaten Bone yang merupakan daerah yang penduduknya adalah suku bugis yang masih kental dengan tradisi Mabbaca- baca, terutama di Kelurahan Ujung Tanah Kecamatan Cenrana Kabupaten Bone. Tradisi Membaca-baca, dalam bahasa bugis Mabbacabaca artinya membaca doa. Jadi Mabbaca-baca dapat kita artikan sebagai proses pembacaan doa. Tapi tradisi Mabbaca-baca ini tidak seperti membaca doa pada umumnya. Doa dibacakan oleh seorang Pembaca (orang yang dipercaya waktu-waktu tertentu, seperti ketika sudah lebaran, setelah panen padi, naik rumah baru, waktu-waktu tertentu untuk meminta keselamatan dan mengucap syukur kepada sang pencipta atas segala yang diberikan. (Wekke, 2013).

Pelaksanaan Mabbaca-baca dilakukan dengan menyediakan berbagai macam makanan, namun makanan yang paling utama disediakan adalah sokko bolong (songkolo hitam) dan sokko pute (songkolo putih), nasu lekku (ayam kampung yang dimasak dengan banyak lengkuas), otti lereng ( pisang ambon), rang tello ( telur rebus), dan masih banyak makanan lain serta yang paling penting dan tidak boleh dilewatkan adalah dupa dan kemenyan. (Salim, 2016).

Di dalam kesempatan, dimana anggota keluarga dan tetangga berkumpul, solidaritas sosial yang berbentuk pemberian makanan yang sudah dibacakan oleh pembaca. Dengan memperhatikan tradisi mabbaca-baca sebagai bagian bentuk siklus sosial masyarakat dan dengan mempertimbangkan bahwa tradisi seperti ini adalah bagian cara anggota keluarga dan anggota masyarakat memindahkan nilai-nilai agama melalui kenangan panjang tentang sejarah sosial kehidupan Nabi Muhammad sebagai Rasul. (Hasanuddin, 2018).

Namun seiring berjalannya waktu berbagai macam spekulasi muncul di tengah masyarakat dengan kehadiran ritual tersebut. Hal ini didasari karena ternyata masyarakat di desa tersebut masih belum paham dengan motif ritual Mabbaca-baca apakah itu dari keyakinan keagamaan atau hanya budaya atau tradisi yang turun-temurun, Selain itu banyak masyarakat yang masih mengaitkan nya dengan hal mistis.(Yuniarti, 2018).

Tradisi sejenis ini memang banyak kita jumpai di berbagai daerah dengan nama yang berbedabeda seperti Penelitian yang dilakukan oleh (Raimatang, 2016) dengan judul "Tradisi Massuro Mabbaca Dalam Masyarakat Rompegading Kecamatan Cenrana Kabupaten Maros", meskipun tujuannya sama yaitu mengucap syukur kepada Allah SWT atas keberkahan dan rezeki yang telah diberikan, ada juga yang melakukannya untuk menolak bala, dan masih banyak tujuan lain. Cara pelaksanaan setiap suku atau daerah juga berbeda masing-masing mempunyai cara tersendiri dan keunikan tersendiri. Dari hasil penelitian terdahulu yang dijelaskan di atas membuat peneliti berusaha untuk memunculkan unsur kebaruan dari penelitian yang akan dilakukan di mana 
fokus utama yang akan diteliti adalah Apa Makna Simbolik Ritual Mabbaca - baca di Kelurahan Ujung Tanah Kecamatan Cenrana Kabupaten Bone.

\section{METODE PENELITIAN}

Pada penelitian ini penulis menggunakan jenis penelitian lapangan (field research) dengan menggunakan jenis penelitian kualitatif. Pada penelitian ini penulis menggunakan Pendekatan Fenomenologi untuk mendapatkan data secara mudah. Schutz berpendapat dalam (Creswell, 1998) menjelaskan bahwa fenomenologi mengkaji bagaimana anggota masyarakat menggambarkan dunia hari-harinya terutama bagaimana individu dengan kesadarannya membangun makna dari hasil interaksi dengan individu lainnya.

Teknik penentuan informan yang dilakukan oleh peneliti dalam penelitian ini adalah teknik purposive sampling. Menurut sugiyono, "teknik pengambilan sampel sumber data dengan pertimbangan tertentu" (Sugiono, 2015). Informan dalam penelitian ini adalah (1) Pabbaca yaitu Sudah melakukan Mabbaca-baca selama kurang lebih 25 tahun. (2) Imam Desa yaitu Sudah melakukan Mabbaca-baca selama kurang lebih 20 tahun. (3) Tokoh Masyarakat : Sudah melakukan Mabaca-baca kurang lebih 25 tahun (4) Masyarakat : Sudah melakukan Mabbaca-baca kurang lebih 23 tahun. Adapun teknik pengumpulan data dalam penelitian ini adalah dengan teknik obsevasi, wawancara, dan dokumentasi. Teknik analisis data dalam penelitian ini adalah dengan reduksi data, penyajian data, dan pengambilan kesimpulan.

\section{HASIL PENELITIAN DAN PEMBAHASAN}

\section{a. Hasil Penelitian}

\section{1) Makna Simbolik Ritual Mabbaca-baca di Kelurahan Ujung Tanah Kecamatan Cenrana Kabupaten Bone}

Menurut Ariftanto dan Maimunah, "Makna adalah arti atau pengertian yang erat hubungannya antara tanda atau bentuk yang berupa lambang bunyi ,ujaran dengan hal atau barang yang dimaksudkan. Berdasarkan pendapat para ahli tersebut maka yang dimaksud makna adalah kata yang terselubung dari sebuah tanda atau lambang, dan hasil penafsiran dan interpretasi yang erat hubungannya dengan sesuatu hal atau barang tertentu yang hasilnya relatif bagi penafsiran.

Kebudayaan itu bukan saja merupakan seni dalam hidup, tetapi juga benda-benda yang terdapat di sekeliling manusia yang dibuat oleh manusia. Itulah sebabnya kemudian kebudayaan diartikan sebagai cara hidup yang dikembangkan oleh sebuah masyarakat guna memenuhi keperluan dasarnya untuk dapat bertahan hidup, meneruskan keturunan dan mengatur pengalaman sosialnya. Kebudayaan adalah ekspresi eksistensi manusia di dunia. Pada kebudayaan, manusia menampakkan jejak-jejak dalam panggung sejarah di zaman modern yang memungkinkan adanya perubahan dalam setiap aspek budaya yaitu dari budaya tradisional menjadi budaya modern.

Setiap kebudayaan yang diciptakan oleh manusia tentunya mengandung makna yang tersirat di dalamnya. Ibarat sebuah simbol, mabbaca-baca tentu tidak hadir begitu saja ditengah masyarakat kabupaten Bone. Seluk beluk kehadirannya tidak bisa dipungkiri kalau tradisi mabbaca-baca dipelopori oleh nenek moyang dan akhirnya dinikmati hingga sekarang. Jadi makna simbolik disini yaitu makna dari setiap yang dilakukan dalam pelaksanaan mabbaca-baca, seperti makna simbol dari sarana mabbaca-baca seperti symbol pisang, songkolo, telur, kemenyan, dan dupa.

Sesuai dengan pernyataan tersebut salah informan yang diwawancarai oleh peneliti selaku sekretaris Lurah mengartikan mengatakan tentang arti mabbaca-baca :

Mabaca-baca merupakan tradisi yang turun temunurun dari nenek moyang (Wawancara I.M,30/04/2021) 
Salah satu pendapat informan selaku sekretaris Lurah mengartikan tradisi mabbaca baca berpendapat bahwa tradisi tersebut adalah hal telah dilakukan sejak dulu yang selalu diberikan kepercayaan kepada penerusnya hingga bisa bertahan sampai sekarang dalam artian bahwa tradisi mabbaca-baca adalah amanah yang diwariskan kepada penerusnya.

Tradisi adalah kepercayaan yang tercipta dari lingkungan yang dipertahan oleh leluhur dimana hal tersebut selalu diamanahkan oleh sala kepercayaannya atau penerus yang lebih mudah dan bisa mempertahankan tradisi tersebut dan juga memiliki daya tarik kepada orang sekitarnya agar tradisi tersebut di tetap bisa diyakini oleh sekitarnya karena tanpa orang sekitar yang mempercayai hal tersebut yakin bahwa tradisi akan hilang jadi intinya bagaimana caranya seorang jadi kepercayaan tetap mempertahankan orang orang disekitar lingkungan tersebut tetap percaya termasuk tradisi mabbaca baca.

Selain itu pendapat yang lain juga di ungkapkan salah satu informan membedakan makna symbol mabbaca-baca uang bernama N.A selaku tokoh masyarakat di kelurahan Ujung Tanah berpendapat bahwa :

"Kalau saya melakukan ritual mabbaca-baca sebagai bentuk/perwujudan dalam memanjatkan doa misalnya dalam meminta keselamatan" (Wawancara N.A 13/05/2021)

Pendapat dari salah satu informan yang berinisial N.A selaku masyarakat yang masih terlibat dalam melaksanakan tradisi Mabbaca-baca di Kelurahan Ujung Tanah Kec. Cenrana Kab. Bone mengungkapkan bahwa Makna simbolik ritual Mabbaca-baca masyarakat desa memaknai ritual Mabbaca-baca sebagai bentuk rasa syukur dan perwujudan dalam memanjatkan doa untuk meminta keselamatan.

Dalam sebuah tradisi dilakukan oleh masyarakat itu bukanlah sebuah tradisi sembarangan yang dilakukan masyarakat karena hal tersebut dalam mindset masyarakat memiliki sebuah arti yang begitu sangat dalam sehingga terkadang masyarakat yang mempercayai tentang tradisi di lingkungan mereka itu sangat emosi ketika ada beberapa orang luar yang tidak paham atau beda pemikiran dan mengata-gatai tradisi mereka adalah hal yang buruk dilakukan, sebenarnya hal tersebut bukanlah atau sebuah tradisi sesuatu hal baru didapatkan sebenarnya hal tersebut sebuah kepercayaan yang telah diwariskan kepada leluhur dan diajarkan kepada penerusnya beserta dengan arti-arti yang begitu sangat luas dan tradisi tersebut telah dipelajari bertahun tahun. Hingga bisa berikan amanah dalam memimpin sebuah tradisi atau biasa disebut sebagai orang kepercayaan dalam membawakan tradisi tersebut.

\section{2) Makna Simbolik Fasilitas dalam Proses Ritual Mabbaca-baca}

Dalam menjalankan sebuah tradisi membutuhkan hal yang dikatakan wajib dalam pelaksanaan ritual mabbaca-baca atau biasa disebut sarana dan prasarana di mana maksud dari prasarana yaitu alat-alat yang digunakan dalam proses mabbaca-baca.

Adapun hasil penelitian yang dilakukan oleh peneliti dengan salah satu informan yang berinisial N.A selaku masyarakat yang masih terlibat dalam melaksanakan tradisi mabbaca baca di Kelurahan Ujung Tanah Kec. Cenrana Kab. Bone mengatakan :

Dalam proses ritual Mabbaca-baca item wajib yang harus disediakan adalah Dupa yang artinya pengantara/pappalettu selamnjutnya kemenyang yang fungsinya sama dengan dupa yang membedakan dari segi bentuk dan kegunaannya( Wawancara N.A, 13/05/2021)

Pendapat dari salah satu informan yang berinisial N.A selaku masyarakat yang masih terlibat dalam melaksanakan tradisi mabbaca baca di Kelurahan Ujung Tanah Kec. Cenrana Kab. Bone mengungkapkan arti mabbaca-baca dari segi bahan dan alat yang paling utama digunakan saat pelaksanaan dimana dia mengartikan bahan dan alat yang digunakan sebagai penyampaian terhadap keinginan atau istilah lainya dalam bahasa umum adalah sebuah doa untuk mengabulkan semua keinginan cdnya saat adakan tradisi mabbaca-baca Aqiqah dan doa 
tersebut disampaikan melalui tradisi mabbaca-baca dengan tujuan agar kedepannya dapat membangun keluarga yang bahagia dan diberikan keselamatan. Adapun makna dari Dupa (dup), paduppa berarti kita melaksanakan upacara tradisi ini, dan memiliki aroma yang sangat wangi yang bermakna agar kita selalu merasakan aroma-aroma positif.

\section{b. Pembahasan}

Secara umum tradisi mabbaca-baca pada masyarakat Kelurahan Ujung Tanah Kecamatan Cenrana Kabupaten Bone masih terlihat dilaksanakan sampai sekarang. Sehingga tidak heran jika adat ini ada yang menganggapnya sah saja, dan sekedar mengikuti. Sehingga dapat ditarik kesimpulan dari penelitian ini yang terkait dengan teori konstruksi sosial bahwa tradisi mabbacabaca masih dianut sampai sekarang. Hal ini karena masih dianggap fungsional bagi sebagaian besar masyarakat Kelurahan Ujung Tanah Kecamatan Cenrana Kabupaten Bone baik itu dalam segi niat maupun pelaksanaannya. Kebudayaan di setiap daerah terkadang memiliki pemaknaan yang sama namun pelaksanaannya itu yang berbeda. Pola-pola unik yang diciptakan masyarakat menjadi daya tarik tersendiri dalam menjalankan warisan dari nenek moyang sehingga berbeda dengan daerah lain. Setiap budaya memiliki caranya sendiri dan tujuannya sendiri dan terlihat dari kebiasaan masyarakat di setiap daerah. Keragaman perbedaan tersebutlah yang menjadikan bangsa kita kaya akan tradisi. Tradisi mabbaca-baca sebelumnya dijelaskan yakni proses dalam memanjatkan doa kepada Tuhan atas nikmat yang diberikan serta sebuah prosesi dalam mendoakan kerabat yang telah dulu kembali ke sisi Allah. Berdoa merupakan hal yang wajib bagi manusia dan pasti akan dilakukan setiap saat. Namun yang memebedakannya adalah cara yang dilakukan dalam proses memanjatkan doa kepada Tuhan.

\section{KESIMPULAN}

Berdasarkan hasil penelitian dan pembahasan tentang Makna Simbolik Ritual Mabbaca baca di Kelurahan Ujung Tanah Kecamatan Cenrana Kabupaten Bone maka dapat ditarik kesimpulan bahwa: (1) Adapun Makna Mabbaca- Baca adalah amanah yang diwariskan kepada penerusnya kemudian arti ma baca baca dari segi bahan yang paling utama digunakan saat pelaksanaan dimana dia mengartikan alat yang digunakan sebagai penyampaian dari segi bahan yang digunakan saat pelaksanaan adalah arti yang paling umum diungkapkan di antaranya memohon perlindungan dan permintaan maaf atas kesalahan yang dilakukan agar kedepannya dapat menjalankan kehidupan dengan tenang (2). Adapun prosesi ritual mabaca-baca adalah Dalam proses mabbaca baca memiliki dua tahapan dimana tahapan pertama adalah tahapan persiapan kemudian dilanjutkan dengan tahapan pelaksanaan saat melakukan prosesi mabbaca baca dimana tahap persiapan tersebut menyiapkan berbagai jenis hidangan wajib saat melakukan prosesi mabbaca baca terkhusus di acara pernikahan dan kedua sarana dimanasara yang dimaksud adalah sebuah doa kemudian semua orang yang ada dilingkungan tersebut dan keluarga yang ada waktunya datang untuk mempersiapkan segala sesuatu yang dibutuhkan, para masyarakat dalam proses mabbaca baca membagi tugas agar saling mempercayai dalam melaksanakan tugas tersebut dan saat melakukan pelaksanaan ritual bacaan diucapkan sudah memang ada yang disiapkan secara khusus saat melakukan ritual apapun itu semuanya sama dan secara otomatis persiapan pun juga dalam melakukan proses membaca juga sama yang bertujuan agara doa yang diutarakan dapat dikabulkan.

Adapun saran dari penelitian ini yaitu (a) Bagi Pemerintah yaitu Semoga dengan penelitian ini pemerintah dapat lebih memperhatikan identitas kebudayaan kabupaten Bone agar tetap terjaga hingga kedepannya dan dijadikan aset Daerah untuk memperkenalkannya kepada daerah lain serta dapat menjadi acuan dalam menentukan sebuah ejaan baru demi masa depan daerah. (b) Bagi Masyarakat, yaitu Diharapkan masyarakat agar tetap menjaga, melestarikan kebudayaannya dan tetap memperkaya khasanah kebudayaan lokal, dengan tuntunan ajaran islam agar tidak ada unsur kemusyrikan serta hal-hal yang menyimpan dari ajaran islam yang 
sesungguhnya, berkat kedatangan islam telah memberi warna baru dlam masyarakat Alelebbae khususnya dalam prosesi pelaksanaan Mabbaca-baca. (c) Bagi Peneliti Selanjutnya Peneliti selanjutnya diharapkan untuk mengkaji lebih banyak sumber maupun referensi yang terkait dengan Makna Simbolik tradisi agar hasil penelitian dapat lebih baik dan lebih lengkap lagi.

\section{DAFTAR PUSTAKA}

Creswell, J. W. (1998). Qualitative Inquiry and Research Design: Choosing among Five Tradition. Sage Publications.

Hasanuddin, U. (2018). Nilai Solidaritas Sosial Dalam Tradisi Mappadendang Pada Masyarakat Paccekke Di Kabupaten Barru.

li, B. A. B., Beatty, A., Hefner, R. W., Mulder, N., Syam, N., \& Manan, M. (2001). LANDASAN TEORI Pengertian Kebudayaan.

Raimatang. (2016). Tradisi Massuro MabBaca Dalam Masyarakat Rompegading Kecamatan Cenrana Kabupaten Maros.

Salim, M. (2016). Adat Sebagai Budaya Kearifan Lokal Untuk Memperkuat Eksistensi Adat Ke Depan. Jurnal Hukum Pidana Dan Ketatanegaraan, 5(2), 224-255. https://doi.org/https://doi.org/10.24252/ad.v5i2.4845

Sugiono. (2015). Metode Penelitian Pendidikan Kuantitatif, Kualitatif, dan R\&D. Alfabeta: Bandung.

Wekke, I. S. (2013). Islam Dan Adat: Tinjauan Akulturasi Budaya Dan Agama Bugis Saat kehidupan diatur dengan pangngaderreng ( undang- masyarakat sampai penaklukan seluruh tanah Bugis tahun 1906 , maka unsur yang awalnya hanya terdiri atas empat kemudian berubah menjadi lim. Analisis, XIII(1), 27.

Yuniarti, D. I. A. (2018). Nilai-Nilai Religius Yang Terkandung Dalam Tradisi Temu Manten Pada Upacara Perkawinan Adat Jawa (Studi Kasus di Dusun Tanduran Desa Jatisari Kecamatan Jatisrono Kabupaten Wonogiri). 